\title{
Can One Learn to Think Critically? - A Philosophical Exploration
}

\author{
Christy Raymond-Seniuk ${ }^{*}, 1,2$ and Joanne Profetto-McGrath ${ }^{1}$ \\ ${ }^{I}$ University of Alberta, Canada \\ ${ }^{2}$ Grant MacEwan University, Canada
}

\begin{abstract}
Within nursing, critical thinking is a required skill that educators strive to foster in their students' development for use in complex healthcare settings. Hence the numerous studies published measuring critical thinking as a terminal outcome of education. However, an important comparison between different philosophical underpinnings such as person, truth and the nature of nursing, and how one defines and utilizes critical thinking in practice, has been absent from discussions about critical thinking and learning. When one views critical thinking with varying philosophical lenses, important questions are raised and discussion is expanded. These questions illuminate different perspectives of critical thinking and attempt to explore whether critical thinking can be learned in nursing. The implications of taking a single philosophical viewpoint and a pluralistic approach to understanding critical thinking and learning are explored.
\end{abstract}

Keywords: Critical thinking, learning, nursing, nursing education, philosophy.

Critical thinking in nursing is complex and described by a mosaic of different definitions. These various definitions have led to confusion about what critical thinking entails [1]. In nursing education, critical thinking is a key objective and/or desired outcome for almost every nursing course and is an aspect of knowledge-based nursing practice evident in Canadian provincial standards [2]. A strong emphasis on the need to develop critical thinking is evident in nursing education despite the lack of an agreed upon definition to guide teaching practice. The variety of critical thinking definitions has also made measurement of students' critical thinking more difficult [3]. To this end, research has been inconclusive as to whether critical thinking results from nursing educational experiences and has called into question whether critical thinking can be learned [4]. Due to the presence of inconclusive literature, a different approach to conceptualizing critical thinking is warranted. Many literature reviews have examined critical thinking and the related definitions and measurement, however none have offered a new lens from which to view similar conclusions $[5,6]$. More specifically, the philosophical underpinnings upon which critical thinking is based should be explored to determine whether critical thinking is a result of nursing education. By using a philosophical inquiry approach, how critical thinking is conceptualized and operationalized in nursing education can be more thoroughly examined.

In this article, we offer a discussion related to the philosophical issue of whether nursing students can learn to think critically. Prompting the need for this exploration was a review of the critical thinking literature in nursing. Articles written in English and published from 2000-2010 focusing on critical thinking in nursing were examined. From those articles, the issues of defining and measuring critical thinking in nursing education were evident. Seminal works that contribute to a definition of critical thinking were

*Address correspondence to this author at the University of Alberta, Canada; Tel: 780-497-5714; E-mail: craymond@ualberta.ca included, as well as articles more specifically related to measurement of critical thinking in nursing education. Narrative articles were also incorporated to represent the current perspectives on critical thinking in a nursing context. Limits to the literature reviewed for this paper include the exclusion of non-English written articles, anecdotal articles describing methods to enhance critical thinking in nursing, critical thinking research articles outside nursing, and other formats of literature including dissertations and unpublished works. This paper is meant as a starting point to spark additional discourse examining concepts, such as critical thinking, using a philosophical approach.

We begin this discussion with a brief overview of what is known about critical thinking in nursing education, more specifically the definitions available in nursing and the predominant results from measurement efforts. Given the more general nature of the nursing education critical thinking literature, a philosophical look at the feasibility of learning critical thinking in nursing is then offered. Using the broader philosophical perspectives of person, knowledge, truth and the nature of nursing, various positions outlining whether a nursing based definition of critical thinking is compatible with learning, are analyzed and discussed. We conclude with suggestions as to how the discipline should proceed, and the potential implications of not examining the philosophical implications associated with learning critical thinking in nursing.

\section{OVERVIEW OF CRITICAL THINKING: DEFINITIONS AND MEASUREMENT IN NURSING EDUCATION}

The multiple definitions of critical thinking highlight various interpretations of what 'thinking critically' is believed to be. These definitions also vary depending on the discipline. For example, the most cited non-nursing critical thinking definitions evident in the literature are those by Facione [7], Brookfield [8], and Paul [9]. Scheffer and Rubenfeld [10], and Alfaro-Lefevre [11] offer the most commonly cited nursing specific critical thinking definitions 
in published literature. Each are included and discussed below.

Facione's [7] critical thinking definition emerged from his work with the American Philosophical Association (APA), which led to the creation of the Delphi consensus statement. This definition states:

We understand critical thinking to be purposeful, selfregulatory judgment that results in interpretation, analysis, evaluation, and inference, as well as explanation of the evidential, conceptual, methodological, criteriological, or contextual considerations upon which that judgment is based... The ideal critical thinker is habitually inquisitive, well-informed, trustful of reason, open-minded, flexible, fair-minded in evaluation, honest in facing personal biases, prudent in making judgments, willing to reconsider, clear about issues, orderly in complex matters, diligent in seeking relevant information, reasonable in the selection of criteria, focused in inquiry, and persistent in seeking results which are as precise as the subject and the circumstances of inquiry permit (p. 4).

Facione's critical thinking definition includes both skills and dispositions and served as the basis for the development of the California Critical Thinking Skills Test (CCTST) and the California Critical Thinking Disposition Inventory (CCTDI). Both tools are commonly used to measure critical thinking in various populations, including nursing students and educators.

Brookfield [8] is also cited for his definition and description of critical thinking. It includes: a) identifying and challenging assumptions; b) challenging the importance of context; c) imagining and exploring alternatives; and d) engaging in reflective skepticism. These components illustrate Brookfield's view of critical thinking as a process with both emotive and rational aspects. Similar to Brookfield, Dewey [12] asserted that reflection resulted from some disbelief in thought. The dissonance in one's thinking then triggers a careful consideration of one's beliefs in order to re-establish beliefs based on knowledge. Similarly, Brookfield identified that reflective skepticism is initiated by imaging and exploring alternatives to problems and situations.

Another critical thinking definition frequently cited in the literature is by Paul [9]. Similar to Facione [7], Paul defines critical thinking including cognitive aspects, more specifically perfections of thought. Paul stated:

Critical thinking is self-disciplined, self-directed thinking that exemplifies the perfections of thinking appropriate to a particular mode or domain of thought. It comes in two forms. If disciplined to serve the interests of a particular individual or group, to the exclusion of other relevant persons and groups, it is sophistic or weak-sense critical thinking. If disciplined to take into account the interests of diverse persons or groups, it is fair-minded or strong-sense critical thinking (p. 10).

The definitions by Facione [7], Brookfield [8], and Paul [9] are non-nursing definitions. Scheffer and Rubenfeld [10] also used a Delphi technique to generate a nursing based definition of critical thinking. This definition will be used as a reference point for this discussion and it states:
Critical thinking in nursing is an essential component of professional accountability and quality nursing care. Critical thinkers exhibit these habits of mind: confidence, contextual perspective, creativity, flexibility, inquisitiveness, intellectual integrity, intuition, open-mindedness, perseverance, and reflection. Critical thinkers in nursing practice the cognitive skills of analyzing, applying standards, discriminating, information seeking, logical reasoning, predicting and transforming knowledge (p.357).

The above definition by Scheffer and Rubenfeld [10] situates critical thinking as an integral part of nursing practice and asserts that both skills and dispositions are required by nurses to think critically. The obvious difference in this definition is the emphasis on intuition, contextual perspective, and creativity as part of how critical thinking is defined in nursing. These more feminine concepts highlight the difference between definitions created from within nursing compared to those more cognitively emphasized and created from outside nursing.

Another nursing definition frequently cited in critical thinking literature is authored by Alfaro-Lefevre [11]. She stated:

Critical thinking and clinical judgment in nursing is: a) purposeful, informed, outcome-focused (results oriented) thinking, b) carefully identifies key problems, issues and risks, c) is based on principles of nursing process, problem solving and the scientific method, d) applies logic, intuition, and creativity, e) is driven by patient, family, and community needs, f) calls for strategies that make the most of the human potential and, g) requires constant reevaluating selfcorrecting, and striving to improve (p. 7). This definition offers a comprehensive description of elements comprising critical thinking from a nursing perspective. It is evident that Alfaro-Lefevre infers a strong link between critical thinking and clinical judgment, which is not evident in other definitions.

Given the various definitions and perspectives, critical thinking is not consistently defined $[3,1]$ and is "not one, monolithic thing" [13, p. 216]. Therefore, the diversity of critical thinking definitions and perspectives is understandable, yet remains problematic for some [14]. Not having a clear conceptualization of what it means to think critically within or outside of nursing is challenging and requires reexamination why and how critical thinking is being operationalized within the discipline.

In nursing critical thinking is often employed as a goal of education, to promote quality nursing care, and positive patient outcomes. Interestingly, the application of this concept as a desirable educational outcome was determined by educational institutions and the academic community to ensure nursing graduates and practicing nurses have the necessary 'skills' to deal with the acuity and complex nature of nursing practice. Moreover, critical thinking is mainly conceived as a cognitive process to assist nurses in managing their expanding knowledge base and to foster the application of knowledge into practice [5]. However, the underlying philosophical implications of critical thinking and whether it can be learned as a cognitive skill or otherwise, has not been explored or discussed in recent literature. 
The predominantly cognitive nature of critical thinking definitions, such as those proposed by Facione [7] and Paul [9] are evident. More specifically, a chiasm of difference has been created between the more cognitive definitions and those definitions emphasizing more feminine aspects, such as those emanating from nursing. For example, critical thinking has been equated with reflection, problem solving, decision-making, clinical judgment and practical reasoning in nursing [15], whereas others believe that critical thinking is a set of more defined thinking skills such as analysis, evaluation, inference, as well as inductive and deductive reasoning [7]. As a result, it appears many authors use critical thinking as a blanket statement to capture its fluid and non-linear nature.

Looking at our reference definition for this discussion, the components of the critical thinking definition offered by Scheffer and Rubenfeld [10] are inclusive of both skills and dispositions. The generalizability of these skills and dispositions; that is, can critical thinking skills and dispositions be transferred to different contexts, is not clear. Generally there is no consensus as to whether critical thinking is contextually specific to nursing. Forneris [16] describes how different philosophers address context but limited discussion occurs whether critical thinking is transferable. Based on Scheffer and Rubenfeld's definition, critical thinking will manifest differently in varying situations and contexts, which makes the task of conceptualizing and operationalizing critical thinking more difficult. In addition to various definitive aspects of critical thinking, the varying philosophical beliefs concerning the nature of the individual responsible for the thinking process also impacts whether one believes critical thinking can be learned. Yet without a fundamental discipline specific definition of critical thinking, it is difficult to measure educational outcomes.

Another problematic aspect of trying to clearly understand critical thinking and its place in nursing education results from attempts to measure it. Measurement of critical thinking in nursing has yielded inconclusive findings. For example, some studies identify significant increases in students' critical thinking following the completion of a nursing education program [17-21]. Yet, other studies reported insignificant increases in critical thinking and unexplained decreases that occurred at certain points in students' nursing programs [22-26]. These contradictory findings require further exploration and understanding to better design and complete future research in this area.

A clear link between nursing education and critical thinking has not been established despite prominent calls for the necessity of critical thinking in nurses and the proof of critically thinking graduates. Ferguson and Day [27] purport that many scholars believe critical thinking is not necessarily a direct outcome of nursing education. Inconsistent and mixed results are evident in many studies examining the critical thinking skills and abilities of students at various points in their nursing education programs. This inconsistency speaks to the need for additional exploration into critical thinking as an outcome of nursing education programs and the potential creation of a nursing specific critical thinking measure $[1,4,26]$. There has been no nursing specific critical thinking measure created to date and given the varied nature of definitions and measurement results, a deeper examination of critical thinking from various perspectives is warranted. By using the concepts of person, truth and nature of nursing, the potential of learning critical thinking is investigated.

\section{THE CONCEPT OF PERSON AND CRITICAL THINKING}

Critical thinking is usually associated with skills and abilities demonstrated at the individual level. As individuals we are unique in personalities and abilities. One philosophical perspective purports that man is a rational and autonomous being [28]. However, it would appear that what makes us similar and different is at the heart of whether one can learn to think critically. More specifically, if individuals are similar, then some aspects of the processes of thinking critically must be similar in order to clearly identify and label such skills and dispositions found in general definitions. These similarities provide a common foundation from which core thinking skills can be defined, taught and hopefully measured. Conversely, the differences in each individual showcase the autonomous and personal nature of applying critical thinking skills in various contexts. Critical thinking may in fact be the application of common cognitive abilities in tandem with each individual's own adaptation and application. We therefore propose that it is through understanding both similarities and differences between individuals that students' critical thinking can be fostered. Different philosophical perspectives on the nature of being offer an interesting starting point to understand whether critical thinking can be learned.

From a reductionist perspective, humans are essentially similar biological beings with brain power regulated by chemicals. Cognitive activity is supported by evidence and as human beings we have more similarities than differences. However, any differences are usually explained by physical changes and validated by science. The assumptions underlying a reductionist perspective on being are that science explains all intellectual activity by reducing each step to a simple, empirically proven brain state [29]. Overall, a reductionist perspective is not compatible with the definition of critical thinking offered by Scheffer and Rubenfeld [10]. More specifically there is a lack of consideration for individuals' non-physical attributes in reductionism that does not resonate with a nursing definition of critical thinking. Furthermore, a reductionist viewpoint does not account for the relational properties human beings exhibit within a larger social context. Although some cognitive processes, such as logic and rational thought can be explained by scientific evidence, the main essence of individuality related critical thinking and the reliance on the specific context of nursing is not explained through reductionist principles. Moreover, a linear scientific viewpoint fails to consider the critical thinking process and the overall goals of nursing. One could not learn anything contextually based or meaning driven (part of thinking critically in nursing) if critical thinking was viewed using this perspective. Although learning of cognitive behavioral skills would be feasible using a reductionist lens, it is unclear whether the less tangible critical thinking skills and 
dispositions could be learned or even valued from this perspective.

Another perspective on 'person' is based on the work of Merleau-Ponty and follows a dualistic approach. Dualism espouses that mind and body are seamlessly connected and that sensory perceptions and motor skills are inseparable [29]. The unified being would then focus on the relationship between oneself and the world, ultimately becoming part of that environment. From a dualistic perspective, each human being experiences the world differently, without similarities to other individuals. Critical thinking in nursing, as defined by Scheffer and Rubenfeld [10], appears incongruent with this perspective. The main reason for this incongruency is the dualistic tendency to focus on one individual's experiences without considering similarities of those experiences to other individuals. Since critical thinking as defined by Scheffer and Rubenfeld predicts and transforms knowledge as one aspect of quality nursing care, it is suggestive of a relational process. Critical thinking based on a dualistic perspective would be so personalized that the overall goal of nursing, doing good for others, would be lost. Individuals could not learn critical thinking from this perspective because they might not consider undertaking similar processes and actions not driven from their own interpretation.

An alternate viewpoint is that of the dependent concept of person where mental and physical states are thought to be closely linked but not inseparable. From this perspective thinking relies on a person's physical state but would not be driven by it [29]. As well, this perspective allows for feelings in addition to brain states to be involved in thinking, through the link with the physical world. The main principle of the dependent position focuses on the cognitive realm being related to the physical self and the physical world. Although it does not specifically say how the mind and body are linked, this perspective allows for mind and body to be somewhat independent from each other where neither the mind nor body can claim full control of one's actions. This perspective embraces the role of self, inclusive of similar physical attributes and unique mental states. Within the nursing context, individuals from this perspective would be able to learn critical thinking through similar cognitive processes as others, with a unique application that would celebrate individual differences. Scheffer and Rubenfeld's [10] definition of critical thinking further supports an independent conceptualization of 'being' by emphasizing individual introspection alongside application of common standards to one's thinking. These are evident in the included definitive elements of reflection and intellectual standards such as those found in Paul's [9] critical thinking definition.

\section{KNOWLEDGE, TRUTH, AND CRITICAL THINKING}

Whenever an individual thinks, it is undoubtedly about something. It is this 'something' that is important in the domain of critical thinking in nursing. How one attains and applies knowledge to one's nursing practice involves critical thinking. As well, how one views truth is an important piece in how knowledge is utilized when thinking critically. In order to better understand how knowledge and critical thinking impact whether one can learn to think critically, the received and perceived viewpoints are compared to Scheffer and Rubenfeld's [10] critical thinking definition.

Based on a received viewpoint of knowledge, information is solely obtained through deductive methods that verify propositions through scientific means and deem valuable facts empirically proven [30]. This viewpoint assumes a general stance that knowledge is value free, objective and quantifiable. From the correspondence perspective of truth, knowledge is proven and justifiable until it is contested and falsified [30]. This view of the Truth (big $\mathrm{T}$ versus small $\mathrm{t}$ ) is based on one objective and removed reality - the pursuit of one universal Truth.

When comparing a nursing critical thinking [10] definition to the received viewpoint, some aspects related to making rational, operational and sound judgments resonate between them. However, the overall complexities in the world of nursing would not be compatible with the unbending nature of knowledge and Truth associated with the received or correspondence viewpoint. Thus, although individuals might be able to learn structured and logical thinking based on empirical knowledge, incorporating values, human situations, and personal feelings into one's thinking would not be supported by those in the received or correspondence camp. Seymour, Kinn, and Sutherland [31] argued against adopting a received or correspondence perspective as it would narrow the reasoning strategies one could use in critical thinking and limit the overall goal of engaging in thinking for mere truth versus understanding. If one adopts a received or correspondence perspective, the important personal attributes and necessary context to critically think in nursing would be rendered unimportant. Based on these viewpoints of knowledge and truth, there would be no room for an individual to learn to think critically as these perspectives do not align with the more feminine skills and dispositions of critical thinking as defined in nursing. If one believes that truth emanates from a variety of sources and ways of knowing in nursing, these philosophical perspectives would not foster the growth of individuals' critical thinking since it only supports an empirically driven reality.

The perceived view acknowledges a value laden nature of understanding and supports knowing from multiple means. The perceived view highlights the individual nature of knowledge construction and emphasizes the need for subjective, intuitive, human factors in both theoretical and practical knowledge [30]. Similar to this viewpoint is the pragmatic perspective on truth, and the existence of probable truths in nursing. This viewpoint is open to numerous understandings and thus various origins of what constitutes truth. The goal of this perspective on truth is to not rely on evidence as defined in the correspondence view, but to examine observations and to respect the humanity, subjectivity, and usefulness of claims [30]. The perceived and pragmatic perspectives on knowledge and truth are congruent with the multiple ways of knowing represented by a nursing based definition of critical thinking. Based on the critical thinking definition provided by Scheffer and Rubenfeld [10], the personal traits of critical thinking include intuition as do the perceived and pragmatic viewpoints. The main goal of the perceived view for knowledge and the pragmatic view on truth is understanding, 
which also resonates and corresponds with the goals of critical thinking in a nursing context. Although critical thinking involves inductive reasoning, it also involves deduction as evident in the received viewpoint. Thus the full cognitive complement of skills that are involved in critical thinking is not necessarily captured entirely with the perceived and pragmatic perspectives.

\section{THE NATURE OF NURSING AND CRITICAL THINKING}

Another important aspect of this debate is how one views the nature of nursing and whether a certain perspective supports critical thinking and is conducive to the facilitation of critical thinking in nursing. Thus far we have discussed the viewpoints on how one might view the concept of person, knowledge and truth. The concept of the nature of nursing offers a macro layer to this discussion, where the overall essence of nursing is brought into the equation.

Is nursing a science, an art, both or none? Nursing is constantly evolving and increasing in complexity. One perspective is that nursing is a science. Johnson [32] categorized nursing from a science perspective and discussed three distinct sub-types: basic, applied or practical. The basic science view supports the attainment of knowledge and Truth as the main goal of nursing [32]. This view does not address the means for obtaining this knowledge but relies solely on description and explanation to make generalizations about nursing. Applied science supports the integration of other disciplinary knowledge into nursing through a resynthesis process [32]. Nursing integrates knowledge from other disciplines to achieve pragmatic outcomes and to develop a more rich and diverse knowledge base. Nursing as an applied science does not foster nursing built solely from knowledge created from within the discipline but supports the ongoing development of nursing knowledge through contributions from other disciplines. Nursing as a practical science embraces truths as a means to an end goal of helping others and doing good. This practical perspective aligns science with art in nursing and uses practical knowledge to presuppose theoretical knowledge [32].

Based on Scheffer and Rubenfeld's [10] critical thinking definition, conceptualizing nursing as a practical science is congruent with the application of scientific and theoretical knowledge to foster the understanding and quality care of individuals within practice. The practical science viewpoint offers the same goal of using critical thinking to integrate truths, which achieve higher order outcomes of quality care. Many would argue that choosing not to use scientificallybased knowledge created to enhance what is known about the world, is immoral and could ultimately cause harm to patients if ignored. Shared principles of analysis, purposeful application, reasoning and action based on principles are evident in both critical thinking and nursing as a practical science. Thus, the learning of critical thinking in a practical nursing context is justifiable and possible due to the congruence of principles and goals. In this sense, students learn to employ theoretical knowledge through critical thinking to meet pragmatic outcomes.

Another perspective supposes that nursing is an art. From this perspective, nursing is more than just the application of science and objective facts. It is the ability to nurse in an artful manner that more specifically encompasses what Johnson [33] regarded as the ability to grasp meaning, establish meaningful connections, skillfully perform nursing activities, rationally determine an applicable course of action, and morally conduct his or her nursing practice (p.1). Johnson [33] suggested that there is no consensus whether one's thinking is part of the art of nursing however discussed the importance of intellectual activity in the performance of nursing care. The importance or irrelevance of thinking as artful practice is not addressed in many philosophical pieces of literature despite many authors' focus on how knowledge is transferred, gained, applied and questioned [33, 34]. From an artful perspective, nursing can be learned in the practice setting and consists of behaviors and intellectual activities that draw upon nursing knowledge applied in a practical sense. Scientific knowledge plays a part in nursing as an art and is used as the antecedent to action [33]. Artful nursing actions are not considered automatic but are more grounded in intellectualism and judged by certain established standards [33]. If nursing is considered an art, nurses' personal traits include intuition, esthetic knowing, sensitivity, and an ability to use past experiences to understand situations would impact how that practice is enacted. In this sense, the nature of nursing as an art is a very fertile ground from which those who think critically can grow. This perspective also supports the view that individuals could learn something as elusive as critical thinking as it mirrors the ambiguity and complexity of an artful nursing environment.

\section{IMPLICATION FOR THE DISCIPLINE}

A discipline can be defined as a branch of knowledge, education or learning that evolves from creative thinking about pertinent issues [35]. The discourse surrounding critical thinking in nursing education is necessary to advance the discipline through questioning and scholarly discussions. By asking and attempting to answer critical questions about critical thinking within the context of nursing, nursing's knowledge base develops and theoretical operationalizations can be explored and tested. To generate and foster the application of nursing knowledge in practice, critical thinking is a necessary skill. As the discipline evolves alongside societal needs, the complexity of health care, increased use of technology, and increased patient acuity requires nurses with well-developed critical thinking. In turn, this requires educational nursing institutions to ensure that its graduates have these higher order thinking skills in order to provide quality patient care and to further the application and questioning of important philosophical issues such as critical thinking within the discipline. Further discussion about whether students can learn critical thinking is at the crux of whether nursing as a discipline should focus on this concept as a valuable and viable outcome in nursing education. We believe, as do others, that critical thinking can be learned to a certain point and that fostering this skill should remain an important aim in nursing education $[5,16,31]$.

It is evident that multiple views exist related to whether critical thinking can be learned in nursing. Not all available views have been discussed in this paper. However, based on the discussions focused on the concepts of person, knowledge, truth and the nature of nursing, we believe some are more aligned with supporting, fostering, and developing 
critical thinking. It is suggested that the discipline should support a pluralistic approach to explain and welcome a variety of perspectives on critical thinking. As situational contexts vary and the nature of nursing varies dependent on the context, critical thinking can transcend these differences and assume a variety of different forms to best suit the situation. We believe that one perspective alone cannot possibly explain and support critical thinking in nursing. Thus the use of pluralism or multiple lenses and perspective is necessary to capture the depth and breadth of the knowledge and essence of what constitutes nursing. Guiliano, Tyer-Voila and Lopez [36] support pluralism and multiple ways of knowing, which translates into supporting unity versus diversity of knowledge. Given the complexity and diversity of nursing, it is feasible and realistic that the philosophical perspectives within nursing are also complex and diverse [37]. Multiple perspectives would more effectively capture the various aspects of critical thinking and could help explain the concept, its principles, and how critical thinking is learned by students.

\section{LOOKING FORWARD}

Whether or not critical thinking can be learned is a difficult topic to philosophically debate. However, this paper has attempted to add to the discussion surrounding this subject and foster a critical spirit of discourse. This issue cannot be solved without further scholarly exploration to uncover and understand the various facets of critical thinking, beginning with a solid conceptual analysis of critical thinking in the literature. Without further attention and questioning, the very vagueness that is thought to plague many definitions of critical thinking and critical thinking research attempting to measure outcomes, will continue to grow and lead to ambivalent operationalization of critical thinking in nursing. This could affect our ability to measure and gauge potential progress and perpetuate the use of the term 'critical thinking' without the necessary knowledge behind it for meaningful application. Although one could advocate for a pluralistic approach to explain the multifaceted nature of critical thinking and its many applications in a nursing context, there are drawbacks to treading this path as well. By not examining specific perspectives further and not analyzing why some perspectives are better suited to the current definition and application of critical thinking, one becomes complacent in accepting that everything has multiple meanings and viewpoints. This perspective can fragment the nursing profession and discipline by raising more questions than answers. Moreover, it would cause confusion among educators and nurses by continuing to use an elusive concept without truly knowing whether it fits within the nursing context. Thus, if we decide to adopt a pluralistic approach, we should do so with caution and with the intent to foster scholarly discussion versus agreeing to disagree without thought. A further incentive for nursing to take a closer look at critical thinking is that much of the literature currently used in nursing derives from other disciplines. More needs to be known about critical thinking in nursing and more specifically how students learn this important skill and its associated attributes.

The goal of this initial philosophical exploration was to further understand critical thinking and the implications of exploring it using different philosophical perspectives. If the discussion ends here we are no further along from where we started. There needs to be additional scholarly attempts to understand critical thinking within nursing by comparing it to various philosophical concepts and previous understanding. By exploring critical thinking philosophically, multiple ways of understanding this important concept are illuminated to better inform whether we think critical thinking can be learned in nursing education.

\section{REFERENCES}

[1] Riddell T. Critical assumptions: Thinking critically about critical thinking. J Nurs Educ 2007: 46(3): 121-6.

[2] College and Association of Registered Nurses of Alberta (CARNA). Nurs Pract Standards. Edmonton, AB: CARNA 2005.

[3] Mundy K, Denham S. Nurse educators- still challenged by critical thinking. Teach Learn Nurs 2008; 3: 94-9.

[4] Brunt BA. Models, measurement, and strategies in developing critical-thinking skills. J Contin Educ Nurs 2005; 36(6): 255-62.

[5] Brunt BA. Critical thinking in nursing: An integrated review. J Contin Educ Nurs 2005; 36(2): 60-7.

[6] Simpson E, Courtney M. Critical thinking in nursing education: Literature review. Int J Nurs Pract 2002; 8: 89-98.

[7] Facione PA. Critical thinking: A statement of consensus for purposes of educational assessment and instructions. Executive summary. The Delphi Report. Millbrae, California: California Academic Press 1990.

[8] Brookfield SD. Developing critical thinkers: Challenging adults to explore alternative ways of thinking and acting. San Francisco: Jossey-Bass 1987.

[9] Paul R. Critical thinking: What, why and how. New Directions for Community Colleges 1992; 77: 3-24.

[10] Scheffer BK, Rubenfeld MG, A consensus statement on critical thinking in nursing. J Nurs Educ 2000; 39(8): 352-9.

[11] Alfaro-Lefevre R. Critical thinking and clinical judgment: A practical approach to outcome-focused thinking $4^{\text {th }}$ ed. St. Louis: Saunders Elsevier 2009.

[12] Dewey J. How we think: A reinstatement of the relation of reflective thinking to the educative process. Boston: Heath 1933.

[13] Walsh CM, Seldomridge LA. Measuring critical thinking: One step forward, one step back. Nurse Educator 2006; 31(4): 159-62.

[14] Tanner CA. What have we learned about critical thinking in nursing? J Nurs Educ 2005; 44: 47-8.

[15] Raingruber B, Haffer A. Using your head to land on your feet: A beginning nurse's guide to critical thinking. Philadelphia, PA: FA Davis 2001.

[16] Forneris SG. Exploring the attributes of critical thinking: A conceptual basis. Int J Nurs Educ Scholarsh 2004; 1: 1-17.

[17] Magnussen L, Ishida D, Itano J. The impact of the use of inquirybased learning as a teaching methodology on the development of critical thinking. J Nurs Educ 2000; 39(8): 360-64.

[18] McMullen MA, McMullen WF. Examining patterns of change in the critical thinking skills of graduate nursing students. J Nurs Educ 2009; 48(6): 310-18.

[19] Ozturk C, Karayagiz Muslu G, Dicle A. A comparison of problembased and traditional education on nursing students' critical thinking dispositions. Nurse Educ Today 2008; 28: 627-32.

[20] Shin R K, Lee JH, Kim KH. Critical thinking dispositions in baccalaureate nursing students. J Adv Nurs 2006; 56(2): 182-89.

[21] Stockard Spelic S, Parsons M, Hercinger M, Andrews A, Parks J, Norris J. Evaluation of critical thinking outcomes of a BSN program. Holistic Nurs Pract 2001; 15(3): 27-34.

[22] Beckie TM, Lowrie LW, Barnett S. Assessing critical thinking in baccalaureate nursing students: A longitudinal study. Holistic Nurs Pract 2001; 15(3): 18-26.

[23] Howell AM, Whitlow JF, Stover LM, Williams Johnson K. Critical thinking as an educational outcome: An evaluation of current tools of measurement. Nurse Educat 1996; 21(3): 23-32.

[24] Noles KM, Nickitas DM, Keida R, Neville S. Does service learning increase cultural competency, critical thinking, and civic engagement? J Nurs Educ 2005; 44(2): 65-70.

[25] Profetto-McGrath J. The relationship of critical thinking skills and critical thinking dispositions of baccalaureate nursing students. J Adv Nurs 2003; 43(6): 569-77. 
[26] Stewart S, Dempsey LF. A longitudinal study of baccalaureate nursing students' critical thinking dispositions. J Nurs Educ 2005; 44(2): 81-4.

[27] Ferguson L, Day RA. Evidence-based nursing education: Myth or reality? J Nurs Educ 2005; 44(3): 107-14.

[28] Cuypers SE. Critical thinking, autonomy and practical reason. J Philos Educ SocGreat Brit 2004; 38(1): 75-90.

[29] Edwards SD. Nursing the person (i): ontology. In S.D. Edwards Philosophy of Nursing: An introduction. New York, NY: Palgrave MacMillan 2001.

[30] Meleis AJ. Theoretical nursing: Development and progress. $4^{\text {th }}$ ed. NewYork: Lippincott 2007.

[31] Seymour B, Kinn S, Sutherland N. Valuing both critical and creative thinking in clinical practice: Narrowing the researchpractice gap. J Adv Nurs 2003; 42(3): 288-96.
[32] Johnson JL. Nursing science: Basic, applied, or practical. Implications for the art of nursing. Adv Nurs Sci 1991; 14(1): 7-16.

[33] Johnson JL. A dialectical examination of nursing art. Adv Nurs Sci 1994; 17(1): 1-14.

[34] Mason M. Critical Thinking and Learning. Educational Philosophy and Theory 2007; 39: 339-349. doi: 10.1111/j.1469-5812.2007.00343.x.

[35] Donaldson SK, Crowley DM. The discipline of nursing. In: Nicoll LH, Ed. Perspectives on nursing theory. Philadelphia, PA: Lippincott 1997.

[36] Guilano KK, Tyer-Viola L, Palan Lopez R. Unity of knowledge in the advancement of nursing knowledge. Nurs Sci Q 2005; 18(3): $243-48$.

[37] Tarlier D. Mediating the meaning of evidence through epistemological diversity. Nursing Inq 2005; 12(2): 126-34.

(C) Raymond-Seniuk and Profetto-McGrath; Licensee Bentham Open.

This is an open access article licensed under the terms of the Creative Commons Attribution Non-Commercial License (http://creativecommons.org/licenses/ by-nc/3.0/) which permits unrestricted, non-commercial use, distribution and reproduction in any medium, provided the work is properly cited. 